\title{
SOCIOBIODIVERSIDADE E BIODEMOCRACIA: UMA (RE) APROXIMAÇÃO DO HOMEM COM A NATUREZA
}

\section{SOCIOBIODIVERSIDAD Y BIODEMOCRACIA: UN (RE) ENFOQUE DEL HOMBRE CON LA NATURALEZA}

\author{
${ }^{1}$ Micheli Capuano Irigaray \\ 2Evilhane Jum Martins
}

\section{RESUMO}

Estabelecer a relação entre sociobiodiversidade e biodemocracia, verificando quais as possibilidades de (re) aproximação do homem com a natureza, nos aspectos de diversidade biológica, cultural e de direitos. Abordagem da sociobiodiversidade e da biodemocracia no contexto da relação do homem com a natureza e das perspectivas de resistências às monoculturas. Método de abordagem crítica, técnica de pesquisa análise bibliográfica. Ao final, afirma-se a necessidade de serem protegidos os direitos da sociobiodiversidade, através da biodemocracia, para além dos interesses econômicos em defesa das questões socioambientais.

Palavras-chave: Sociobiodiversidade, Biodemocracia, Monoculturas

\section{Resumen}

Establecer la relación entre el sociobiodiversidad y biodemocracia, comprobar la potencia de enfoque ( re) del hombre con la naturaleza, en los aspectos de la diversidad biológica, y los derechos culturales. Sociobiodiversidad aproximación y biodemocracia en la relación del hombre con la naturaleza y el contexto de las perspectivas de la resistencia a los monocultivos. Método de enfoque crítico, la investigación técnica revisión de la literatura. Al final, se afirma la necesidad de que los derechos de sociobiodiversidad protegida por biodemocracia , además de los intereses económicos en defensa de las cuestiones ambientales.

Palabras-claves: Sociobiodiversidade, Biodemocracia, Los monocultivos

1 Mestranda em direito na Universidade Federal de Santa Maria. Advogada. Universidade Federal de Santa Maria UFSM, Rio Grande do Sul. Brasil - E-mail: capgaray@brturbo.com.br

${ }^{2}$ Mestranda em direito na Universidade Federal de Santa Maria. Advogada. Universidade Federal de Santa Maria UFSM, Rio Grande do Sul. Brasil - E-mail: evilhane martins @ hotmail.com 


\section{INTRODUÇÃO}

$\mathrm{O}$ antagonismo entre meio ambiente e desenvolvimento vem se destacando no cenário global, principalmente a partir da década de 70, colocando em dúvida o modelo de desenvolvimento, marcado pelo avanço tecnológico, e apropriação dos recursos naturais, pela biopirataria (SANTILLI, 2004, p.349). Os países do Sul são considerados como os mais vulneráveis, pelo domínio econômico dos países do Norte e pela grande influencia das indústrias farmacêuticas e transnacionais, com grande interesse na exploração da biodiversidade dos países tropicais, chamados como "mega diversos", pela rica e variada diversidade biológica e cultural.

A América Latina e, especialmente, o Brasil sofrem constantemente evasão de sua biodiversidade, sendo que o grande interesse nesse cenário é a floresta Amazônica pelo seu grande potencial de biodiversidade e conhecimento dos povos tradicionais. As novas formas de tecnologias e o discurso hegemônico dos países do norte, de cunho eurocêntrico e dominador, resultou em uma devastação ambiental e na ameaça aos grupos que vivem nessas áreas. Muitos desses grupos, ainda representam uma forma de resistência à imposição de saberes da monocultura, preservando sua biodiversidade e seus conhecimentos locais, tão ameaçados pelo desenvolvimento e pelos conflitos ambientais (ZHOURI, LASCHEFSKI, 2010. p. 11-12).

Nesse contexto, o objetivo da presente pesquisa é analisar a relação da sociobiodiversidade e da biodemocracia, para uma possível (re) aproximação do homem com a natureza, observando-se os aspectos de diversidade biológica, cultural e de direitos. A problemática da pesquisa consiste em analisar quais as possibilidades da sociobiodiversidade e da biodemocracia, auxiliarem nesta (re) aproximação do homem com a natureza, na busca de um novo paradigma em oposição ao atual modelo de desenvolvimento insustentável de monoculturas.

Assim, pretende-se analisar no primeiro capitulo a sociobiodiversidade enquanto contexto de diversidades culturais, naturais e de direitos, no segundo, a biodemocracia no contexto da relação do homem com a natureza e, no terceiro, as perspectivas da Sociobiodiversidade e Biodemocracia como resistências às monoculturas. Utilizando-se uma abordagem crítica, quanto ao atual cenário da crise ambiental, e a necessidade de uma (re) aproximação do homem com a natureza, e como técnica de pesquisa análise bibliográfica, fichamentos e resumos. 
Nesse enfrentamento, a sociobiodiversidade será analisada em seus aspectos de diversidade biológica, cultural e de direitos, associando-se a biodemocracia, como forma de resistência às monoculturas e ao poder hegemônico de dominação dos países do Norte sobre os países do Sul, e a verificação de uma possível (re) aproximação do homem com a natureza.

\section{SOCIOBIODIVERSIDADE ENQUANTO CONTEXTO DE DIVERSIDADES CULTURAIS, NATURAIS E DE DIREITOS}

Os problemas ambientais estão se agravando nas últimas décadas, pelo aumento de poluição, avanço da tecnologia, extinção da biodiversidade, consumo insustentável, grande geração de resíduos sólidos entre outros, surgindo assim, a emergência do direito ser um balizador capaz de garantir os direitos da sociobiodiversidade (ARAUJO, 2013, p. 270).

No atual mundo globalizado, da prevalência do poder de dominação hegemônico eurocêntrico dos países do Norte sobre os países do Sul, surge a necessidade de reflexões, quanto à crise ambiental vivenciada, e o importante papel da ecologia de saberes na transformação dos critérios de validade do conhecimento, reconhecendo outros saberes, como os conhecimentos locais. Nessa busca pelo reconhecimento de diversidades culturais, a ecologia de saberes poderá nortear a validação de conhecimentos, para além do conhecimento científico, para além do poder hegemônico, promovendo uma superação da colonização e do domínio da informação manipuladora. Estes elementos emergem na busca de respostas, de novos paradigmas, de uma reconstrução epistemológica, da valorização da ecologia de saberes, de uma nova economia global, de uma nova observação da comunicação ecológica.

Pensar em ecologia e sistemas de saberes desaparecidos traz reflexões sobre a relação do homem com a natureza, sobre a transformação e apropriação dessa natureza, e, sobre as possibilidades de se restabelecer a unidade perdida. Nesse pensar ecológico, Moscovici (2007. p. 31-33) reflete sobre a necessidade dos movimentos ecológicos estarem relacionados com a política, e observa que nossa política não se ocupa da sociedade ou da natureza, mas da relação entre elas, pela exploração contra a natureza, e de sua transformação pela violência, um penar e agir de dominação, admitindo-se que a técnica e a ciência, o psiquismo, as doutrinas filosóficas, são impregnadas por essa separação e esse antagonismo que prevalece em nossa atualidade. 
Moscovici (2007. p. 34) ainda observa o nosso mal-estar de viver, de destruição, da obsessão pela produtividade, das escolhas dos modos de produção inadequados. Essas preocupações foram levantadas pelos ecologistas, na busca pelo desenvolvimento sustentável, pelo resgate de culturas e valorização dos movimentos ecológicos não vinculados ao poder de dominação dos interesses econômicos, Shiva (2003. p. 11-12) alerta que o verdadeiro desenvolvimento, tem que ser ecológica e socialmente sustentável, com respeito à biodiversidade.

Assim, o risco de desaparecimento de culturas e saberes vem refletindo de forma decisiva no cenário geopolítico, fazendo imperar culturas e formas de apropriação da biodiversidade, servindo aos interesses das transnacionais e do mercado econômico. $\mathrm{O}$ conhecimento científico - tecnológico, apresenta-se em oposição ao conhecimento tradicional, gerando o bioimperalismo, analisado por Shiva ((2003. p. 11) pelo não reconhecimento de saberes locais, os quais são descritos por Vieira (2012, p. 111), como saberes cujas expressões culturais dos povos tradicionais são ensinadas de geração em geração, como prática de vida, integrando a própria identidade da comunidade, intrínseca aos seus indivíduos.

Nesse contexto Shiva (2003, p. 15-16) reflete sobre as causas do desaparecimento da diversidade e o desafio de sua preservação, relacionando que a principal ameaça à vida em meio à diversidade, deriva do hábito de pensar em termos de monoculturas, denominados "monoculturas da mente". Essas monoculturas fazem desaparecer da percepção e consequentemente do mundo, alternativas de resistência e do enfrentamento do poder hegemônico. A não preservação da biodiversidade resulta nas reações em cadeia, de modo que o desaparecimento de uma espécie está relacionado à extinção de inúmeras outras com as quais esta inter-relacionada por meio de redes e cadeias alimentares e sobre as quais a humanidade é totalmente ignorante (SHIVA, 2003, p. 15-16). Destacando ainda que o fortalecimento dos governos do Sul, de sua biodiversidade e de seu povo, deve ser pautado na proteção dos direitos democráticos à vida, de substituição do regime de bioimperalismo, para um regime de biodemocracia, com quem respeita e cultiva a biodiversidade (SHIVA, 2003, p. 114-115).

No mesmo sentido Ost (1995, p.104) analisa a ecologia de saberes versus o poder hegemônico Norte-Sul, como consequências de uma natureza gerada, apropriada e transformada pelo homem, de uma ecologia e ciência global e do complexo, em que é preciso conhecer e compreender os ritmos, os ciclos e o equilibrio desta natureza, alertando ainda, para a 
destruição sistemática das espécies, do dualismo que determina a perda do vínculo com a natureza e ao mesmo tempo suscita a ilimitabilidade do homem e sua irresponsabilidade com nosso habitat. A lei da bipolaridade dos erros reflete sobre o cerne da questão, de que não é a terra que pertence ao homem, mas o homem é que pertence a terra. Esse resgate de identidade cultural, de saberes, de ruptura dos padrões de imposição para o consumo, de monoculturas, de herança intelectual, representa-se como uma forma de emancipação social, contra a repressão dominante, surgindo assim, atitudes de questionamentos, debates e informações adequadas sobre as questões ambientais, riscos e saberes, com a participação democrática e políticas públicas de acesso à informação ambiental, nas suas multidimensões e espaços territoriais, de reconhecimento do homem como parte da natureza.

Esse poder de dominação Europeu “colonizador”, segundo Quijano (2005, p. 121) representou a incorporação de tão diversas e heterogêneas histórias culturais a um único mundo dominado pela Europa, significou para esse mundo uma configuração cultural, intelectual, e intersubjetiva, equivalente à articulação de todas as formas de controle do trabalho em torno do capital, para estabelecer o capitalismo mundial. Com efeito, todas as experiências, histórias, recursos e produtos culturais terminaram também articulados numa só ordem cultural global em torno da hegemonia europeia ou ocidental. Estabelecendo um novo padrão de poder mundial, a Europa também concentrou sob sua hegemonia o controle de todas as formas de controle da subjetividade, da cultura, e em especial do conhecimento, da produção do conhecimento.

Assim, a diversidade biológica, tem que ser tratada mais seriamente como um recurso global, segundo Wilson (1997, p. 03) esse tratamento de forma global, insurge-se para que a biodiversidade seja registrada, usada e acima de tudo preservada. Essa emergência do direito como balizador na preservação da biodiversidade deve-se ao fato do crescimento explosivo populacional, que provoca um desgaste acelerado do meio ambiente, especialmente nos países tropicais, como também, o fato da ciência estar descobrindo novas utilizações para a diversidade biológica, e de grande parte da diversidade estar se perdendo irreversivelmente através da extinção causada pela destruição de seu habitat natural. Tanto o direito, como a política e a economia, necessitam de um novo paradigma social, norteador da relação do homem com a natureza, de uma biodemocracia com quem respeita/cultiva a biodiversidade conforme demonstrado por Shiva, ao descrever a possibilidade de um desenvolvimento ecológico e socialmente sustentável (2003, p. 11). 
Wilson ainda alerta para o fato de não sabermos o verdadeiro número das espécies sobre a Terra, com a indicação que cerca de 1,4 milhões de espécies vivas de todos os tipos de organismos já foram descritas, sendo aproximadamente 750.000 são insetos, 41.000 são vertebrados e 250.000 são plantas, o restante consiste de um vasto complexo de invertebrados, fungos, algas e microrganismos (1997, p. 4).

O Relatório da ONU, de Desenvolvimento Humano, apresentado pelo Programa das Nações Unidas para o Desenvolvimento (Pnud), prevê catástrofe ambiental no mundo em 2050, divulgando que ao fim dos próximos 37 anos, são estimadas mais de 3 bilhões de pessoas vivendo em situação de extrema pobreza, das quais pelo menos 155 milhões estariam na América Latina e no Caribe. E essa condição demográfica e social seria motivada também pela degradação do meio ambiente e pela redução dos meios de subsistência, como a agricultura e o acesso à água potável (ONU, 2013).

Sachs observa que quanto aos padrões de consumo no Sul, existe a reprodução dos padrões de consumo do Norte, em benefício de uma pequena minoria, nessa perspectiva a democratização do desenvolvimento, o paradigma necessita ser completamente mudado. Por princípio, o Sul poderia ter evitado alguns dos problemas que estamos atravessando no Norte se tivesse pulado etapas em direção à economia de recursos, orientada para os serviços e menos intensamente materializados, em prol do meio ambiente e da elevação do padrão de pobreza. No entanto, é improvável que isso aconteça sem sinais claros de mudanças no Norte em relação ao efeito demonstrativo dos seus padrões de consumo sobre a população do Sul, maximizados pelos processos de globalização em âmbito cultural (2008, p.58).

A proteção ao meio ambiente esta prevista no artigo 225 da Constituição Federal Brasileira, sendo que os artigos 215 e 216 visam à proteção da sociodiversidade, conforme Santilli (2005, p. 75) consagram a ideia de que o patrimônio cultural abrange os bens cultura is referenciadores dos diferentes grupos formadores da sociedade brasileira, valorizando a rica sociobiodiversidade (ARAUJO, 2013, p. 279) brasileira, e o reconhecimento das expressões culturais de diferentes grupos sociais na formação da identidade cultural brasileira. Observandose ainda, que o artigo 231, da Constituição, dispõe sobre a prévia consulta das comunidades indígenas, como forma de assegurar a plurietnia de nossa nação (KISHI, 2004, p.

337) e a Lei 13.123, de 20 de maio de 2015, que regulamenta o artigo 225 da Constituição e os artigos 15 e 16 da CDB, que dispõe sobre o acesso ao patrimônio genético, sobre a proteção e o acesso ao conhecimento tradicional associado e sobre a repartição de benefícios para conservação e uso sustentável da biodiversidade (BRASIL, 2015). 
Nesse contexto, destaca-se a emergência de proteção dos direitos da sociobiodiversidade, que conforme Araújo (2013, p. 269-270) representa uma proteção da diversidade biológica, cultural e de direitos, sendo que o artigo 215 da Constituição Federal Brasileira estabelece a proteção ao patrimônio cultural brasileiro dos bens de natureza material e imaterial, incluindo as formas de expressão, os modos de criar, fazer e viver e as criações científicas, artísticas e tecnológicas dos diferentes grupos sociais brasileiros (SANTILLI, 2005, p. 78). No mesmo sentido o artigo $8^{\mathrm{o}}$ alínea (j) da CDB, dispõe sobre a definição de conhecimentos tradicionais associados como sendo conhecimentos, inovações e práticas das comunidades locais e populações indígenas com estilo de vida tradicional relevantes à conservação e à utilização sustentável da diversidade biológica (BRASIL, 1998).

A proteção do patrimônio cultural recebe respaldo também, na Declaração Universal sobre a Diversidade Cultural em 2002, reconhecendo o diálogo entre as culturas e as civilizações na defesa da diversidade cultural das minorias e dos povos tradicionais e na Declaração para salvaguarda do Patrimônio Cultural e Imaterial de 2003, na defesa dos conhecimentos e expressões das comunidades, em especial as indígenas. Em 2005 a Convenção sobre a Proteção e promoção da Diversidade das Expressões Culturais, na defesa e proteção da diversidade cultural das minorias e dos povos indígenas, sendo que no Brasil a Convenção foi promulgada através do Decreto $n^{\circ}$ 6.177, de $1^{\circ}$ de agosto de 2007 (BRASIL, 2007), dispondo sobre a proteção e promoção da diversidade das expressões culturais (UNESCO, 2015).

Sendo assim, os direitos que envolvem a sociobiodiversidade, os quais dizem respeito às questões de diversidades biológicas, culturais e de direitos, estão inseridos nos contextos sociais e jurídicos que envolvem as comunidades tradicionais recebam o reconhecimento da aplicação dos direitos humanos e culturais previstos na ordem internacional e constitucional. Observando-se ainda, a necessidade e urgência de preservação do contexto cultural e ecológico, através de uma política capaz de reduzir desigualdades, valorizar as diversidades culturais, reconhecendo os conhecimentos dos povos tradicionais, e dando mais atenção as minorias.

Somente pelo respaldo e reconhecimento desses direitos sobre a diversidade cultural e das sociedades tradicionais, considerando a sociobiodiversidade, como resultado da soma de natureza mais sociedade, de seu reconhecimento como categoria jurídica, e o reconhecimento do consentimento prévio informado e a repartição de benefícios como pressupostos indispensáveis para garantir o uso sustentável da biodiversidade e do respeito ético o moral 
das sociedades detentoras de praticas culturais e de sua organização social, de preservação do meio ambiente às futuras gerações.

\section{BIODEMOCRACIA NO CONTEXTO DA RELAÇÃO DO HOMEM COM A NATUREZA}

A relação do homem com a natureza vem merecendo destaque, pela crise ambiental acentuada nas últimas décadas, por um modelo insustentável de desenvolvimento, moldado pelo domínio e apropriação dos recursos naturais, surgindo assim, à necessidade de buscar um novo paradigma, um novo modelo capaz de nortear o convívio do homem com a natureza, respaldados pelo princípio de solidariedade. A biodemocracia (SHIVA, 2003, p. 115) envolve esse princípio de solidariedade, quanto ao reconhecimento de um valor intrínseco a todos os seres vivos e seus respectivos direitos, bem como ao reconhecimento dos direitos originários dos povos tradicionais, relativos aos seus conhecimentos e modos de exploração da biodiversidade.

Na América Latina, por ser cenário de países mega diversos, que concentram uma rica e variada biodiversidade (MARTINS, 2009, p. 15-16), os reflexo do bioimperalis mo (SHIVA, 2003, p. 11), do poder eurocêntrico (SANTOS, 2009, p. 283) de dominação hegemônica dos países do norte sobre a biodiversidade dos países do sul, são sentidos de forma drástica, provocando um desequilîbrio ambiental e um agravamento da crise no atual modelo de desenvolvimento. Somente o Brasil detém $50 \%$ da biodiversidade do mundo e um vultoso patrimônio em recursos de biodiversidade (SHIVA, 2003, p. 14), sendo um país tropical de dimensões continentais, e de uma enorme diversidade de biomas que abrigam alta riqueza de espécies (MARTINS, 2009, p. 57), são fatos extremamente relevantes no contexto global, que provocam uma emergência na reflexão quanto à necessidade de um novo modelo no aspecto político, social, econômico e jurídico para pensar a relação do homem com a natureza, (re) pensar a ecologia e os ecossistemas, que são fonte de vida na terra. 
Capra destaca que a questão dos valores é fundamental para a ecologia profunda ${ }^{1}$, observando que a ética ecológica profunda é urgentemente necessária nos dias de hoje, especialmente na ciência, uma vez que a maior parte daquilo que os cientistas fazem não atua no sentido de promover a vida nem de preservar a vida, mas sim no sentido de destruir a vida. Salientando ainda que na realidade, os fatos científicos emergem de toda uma constelação de percepções, valores e ações humanos, dos quais não podem ser separados, sendo assim, os valores são inerentes para proteção de toda a natureza viva, alicerçando na experiência profunda, ecologicamente ou espiritual, o fato da natureza e o eu serem um só (2006, p. 28-29).

A biodemocracia insere-se nesse contexto do vínculo entre a percepção ecológica do mundo e o comportamento do homem nessa relação complexa e interconectada, insurgindo-se contra as formas de dominação, de apropriação dos recursos naturais, traçando um novo paradigma para nortear essa relação.

Moscovici também observa a polimerização ${ }^{2}$ da ecologia, na relação do homem com a natureza, em que o homem é fruto do meio, vivemos o presente de uma geração que viveu a guerra e a destruição, que viu proliferar a cultura da morte, do capital como eixo central de equilibrio e coexistência, servindo aos interesses ditos pacíficos, para Europa garantir seus arsenais nucleares, enquanto americanos e soviéticos negociavam a melhor forma de exterminar todos os seres vivos do planeta. O fracasso desta modernidade vem fazendo surgir a emergência de libertar o mundo dos homens para governar apenas coisas, para um laço de reconhecimento e proximidade do homem com a natureza, pelo principio da solidariedade e da biodemocracia, que seja capaz de permitir ao homem a informação necessária e ética na tomada de decisões, quanto ao atual modelo econômico proposto para o desenvolvimento (2007, p. 15-16). A informação correta, ética e imparcial, quanto aos reais impactos da ciência, refletem a preocupação de Mocovici, em uma crítica à ciência, que nos coloca frente a um grande dilema: como a pesquisa da verdade e as exigências da racionalidade podem se conciliar com as possibilidades de destruição do mundo natural? Quais as reais possibilidades de pensarmos a natureza e a sociedade, sem a existência da luta contrária, da oposição e sobreposição, de apropriação e destruição da natureza e do próprio homem?(2007, p. 16-18).

\footnotetext{
${ }^{1}$ Ecologia profunda, segundo Capra, refere-se à percepção ecológica profunda, reconhecendo a interdependência fundamental de todos os fenômenos, e o fato de que, enquanto indivíduos e sociedades estão todos encaixados nos processos cíclicos da natureza: somos todos dependentes desses processos.

${ }^{2}$ Polimerização, da química: união de diversas moléculas idênticas que conduz à produção de um corpo novo, com peso molecular mais elevado.
} 
Moscovici, ainda reflete sobre o fato dos ecologistas fazerem política e sobre a visão da sociedade, sendo assim, descreve a sociedade como global e com o objetivo de desenvolvimento, com uma ação cultural e política que coloca em oposição: homem x natureza, como se a natureza fosse um simples reservatório de recursos, dada visão holística do homem frente à natureza, vendo-se como um ator biológico e social, sem perceber que a natureza faz parte de nossa história e o homem uma parte dela. Nesse limite de separação e de oposição entre sociedade e natureza, surge à necessidade de restabelecer a unidade quebrada ou perdida, entre duas partes de uma mesma existência, de uma política baseada na biodemocracia, capaz de impedir que se perpetue a indiferença diante da natureza, de uma (re) organização das cidades, da educação, da produção, de uma política pedagógica, invertendo- se a tendência de destruição das cidades e dos campos (2007, p. 31-32).

A preservação da biodiversidade com base na ecologia e na justiça traz uma abordagem ecologicamente sustentável, interrompendo a ajuda e os incentivos à destruição dos recursos naturais, acabando com os subsídios e assistência pública à substituição da diversidade por sistemas centralizados e homogêneos de produção na silvicultura, na agricultura, na pesca e na criação de animais (SHIVA, 2003, p. 110-111). Retirar a possibilidade de escolha, e manutenção das práticas das comunidades locais, pode ser o maior afronto a sobrevivência da natureza, a imposição de um sistema de monoculturas, acaba com a memória de um povo, com sua cultura, sua ligação mais intrínseca com suas raízes, com o meio no qual esta inserido. Esses efeitos devastadores são contrários ao processo da (bio) democracia, de um novo olhar democrático e participativo das comunidades sobre a natureza, sobre o meio na qual estão inseridas, que possibilite uma diversidade de culturas, de resgates de sua valorização e participação efetiva nos frutos advindos dos conhecimentos dos povos tradicionais, protegidos pela CDB - Convenção de Diversidade Biológica. 
Observando-se que as normas constantes na $\mathrm{CDB}^{3}$ podem ser identificadas como soft law, diante da ausência do caráter coercitivo ou possibilidade de aplicação obrigatória aos Estados, mas segundo Vieira ( 2012, p. 57) isso não impede que sejam produzidos efeitos jurídicos, à medida que normatiza o comportamento político dos Estados com a construção paulatina de um regime jurídico de proteção da biodiversidade, o qual deve interagir com o regime jurídico dos direitos de propriedade intelectual - Trips ${ }^{4}$, promovendo um equilibrio na proteção da biodiversidade, para o uso sustentável e repartição dos benefícios decorrentes dessa utilização. Emergindo assim, a necessidade de buscar restabelecer os direitos da sociobiodiversidade, através de um novo olhar, amparado na biodemocracia, que permita a oportunidade e o reconhecimento dos conhecimentos das comunidades tradicionais, quanto a sua efetiva participação nos resultados advindos pela exploração de seus recursos naturais e conhecimentos da biodiversidade.

Entre esse conflito de proteção da biodiversidade e de sua exploração, da venda da biodiversidade, traz a busca de interação entre a CDB com o Trips, na necessidade de obtenção de um regime Sui Generis descrito por Vieira como um regime de proteção da biodiversidade, distinto do sistema multilateral e com o reconhecimento dos diretos dos povos tradicionais aos seus conhecimentos nesse sistema. Um novo regime para proteção da biodiversidade latino-americano, que proteja os saberes tradicionais na categoria de direitos congênitos $^{5}$, com capacidade de contraposição ao regime internacional de propriedade intelectual (2012, p. 181).

Na análise de Shiva (2003, p. 86-88), os conhecimentos ecológicos profundos e sofisticados da biodiversidade, são como regras culturais, exemplificando o desaparecimento de safras e cultivos, da substituição da biodiversidade por monoculturas, segundo esse paradigma dominante de produção ou do assalto aos recursos genéticos do Terceiro Mundo (2003, p. 104), pela pressão das grandes companhias farmacêuticas, refletindo a violência desencadeada contra os sistemas locais de saber, que não é considerado como um saber, observando-se que a invisibilidade é a primeira razão pela qual os sistemas locais entram em colapso, antes de serem testados e comprovados pelo confronto com o saber dominante do Ocidente (2003, p. 22).

\footnotetext{
3 BRASIL.Con venção sobre Diversidade Biológica-CDB- Decreto Legislativo nº 2, de 1994 Aprova o texto da Convenção sobre Diversidade Biológica, assinada durante a Conferência das Nações Unidas sobre Meio Ambientee Desenvolvimento, realizada na cidade do Rio de Janeiro, no período de 5 a 14 de junho de 1992. Decreton. 2.519, de 13 de março de 1998.

${ }^{4}$ BRASIL. TRIPS- Decreto n.1.355, de 30 de dezembro de 1994. Promulga a at a final que incorpora os result ados da rodada Uruguai de negociações Comerciais Multilaterais do GATT.

5 Direito Congênito - abarca o acervo coletivo patrimonial, cultural, territorial, histórico, econômico, e teria em sua composição a interrelação das práticas culturais tradicionais e a construção de saberes, a partir dos quais o devir histórico das comunidades tradicionais é possibilitado, colaborando, para uma constante atualização dos saberes na reafirmação da identidade própria de cada população tradicional.
} 
Sendo assim, a força de resistência pela sobrevivência da biodiversidade, ainda persiste na ecologia de saberes, de culturas, da preocupação com os efeitos da informação na economia, na política e nas relações de poder. Nesse fluxo de compreensão espacial, de relações em tempo real, de refletir sobre uma sociedade de risco e as consequências dessa modernidade, com uma intensa produção de conhecimentos, de uma lógica da técnica, devemos buscar uma democratização do saber, pela cidadania e emancipação social, capaz de produzir a redução das desigualdades, da produção de novas respostas aos modelos impostos, de minimizar os efeitos de uma colonização do saber, amparados na biodemocracia para preservação da biodiversidade com base na ecologia e na justiça.

\section{PERSPECTIVAS DA SOCIOBIODIVERSIDADE E BIODEMOCRACIA COMO RESISTÊNCIAS ÀS MONOCULTURAS}

Na perspectiva de um novo olhar, de um novo paradigma para tratar as questões ambientais, na atual sociedade global informacional, em que devem ser consideradas não somente suas complexidades e riscos, mas também os aspectos socioculturais emergem direitos que visam atender às novas expectativas de desenvolvimento. Nesse sentido, os direitos da sociobiodiversidade e biodemocracia, podem ser considerados como formas de resistências ao domínio econômico, ao poder hegemônico de dominação dos países do Norte sobre os países do Sul, do avanço das monoculturas.

O processo de monoculturas e de apropriação da natureza tomou relevância, através das indústrias da biotecnologia que avançaram na utilização de conhecimentos de povos tradicionais, desenvolvendo atividades relacionadas à biopirataria, etnobiopirataria (PORTOGONÇALVES, 2012, p. 317) e bioprospecção (TYBUSCH, 2015, p. 158). Tais atividades envolvem a utilização e o acesso aos recursos genéticos de um determinado país ou aos conhecimentos tradicionais associados a tais recursos genéticos, em desacordo com os princípios estabelecidos na Convenção de Diversidade Biológica (SANTILLI, 2004, p. 346).

Em oposição a este padrão eurocêntrico de imposição colonizadora que tem a prevalência das monoculturas, surge o saber ambiental, como epistemologia política, na busca dar sustentabilidade à vida, na compreensão desse saber concentram-se as identidades culturais, do próprio ser para além de sua condição existencial, de mobilização dos atores sociais para uma construção de estratégias alternativas de compartilhar saberes, diferenças e de um diálogo entre saberes favoráveis à sustentabilidade e emancipação social. Shiva ainda observa que o 
verdadeiro desenvolvimento só pode ser um desenvolvimento ecológica e socialmente sustentável, se for pautado em políticas estratégicas de desenvolvimento para sair do que ela chama de bioimperalismo, que impõe as monoculturas, e construir a biodemocracia com quem respeita e cultiva a biodiversidade, salientando que a principal ameaça à vida em meio à diversidade deriva do habito de pensar em termos de monoculturas, sendo assim, necessário enfrentar a dicotomia universal/local, que é desvirtuada quando aplicada às tradições do saber ocidental e autóctone porque a tradição ocidental é uma tradição que se propagou pelo mundo inteiro por meio da colonização intelectual (2003, p.11). Nesse processo de descaracterização dos saberes locais, de saberes desaparecidos, as monoculturas, apresentam-se como mecanismos de redução e de controle da natureza, de prevalência do conhecimento técnico- científico, de destruição da diversidade, das sementes, do imperialismo de tecnologias ditas milagrosas para novas técnicas de produção, como sementes capazes de resistir a tudo, as mudanças climáticas e as pragas.

Assim, as alternativas como dos sabres locais, ligados a terra, diversidades culturais de comunidades, auxiliam nos resgates de suas memórias, para que descubram novas maneiras de relação com a natureza, de culturas diversificadas como uma forma de tirar o sustento e preservar a biodiversidade. Shiva (2003, p. 86-88) analisa que os conhecimentos ecológicos profundos e sofisticados da biodiversidade, são como regras culturais, exemplificando o desaparecimento de safras e cultivos, da substituição da biodiversidade por monoculturas, segundo o paradigma dominante de produção ou do assalto aos recursos genéticos do Terceiro Mundo pela pressão das grandes companhias farmacêuticas. O primeiro plano da violência desencadeada contra os sistemas locais de saber é não considera-los um saber, a invisibilidade é a primeira razão pela qual os sistemas locais entram em colapso, antes de serem testados e comprovados pelo confronto com o saber dominante do Ocidente (2003, p. 104).

Considerando essa relação entre a diversidade biológica e cultural, observa-se que ambas são essenciais para sustentabilidade global, a partir da sociobiodiversidade, para um desenvolvimento com equilibrio na relação do homem com a natureza, de uma biodemocracia que promova uma condição ecocidadã, em que os recursos naturais estejam à disposição de todos, independentemente de sua condição socioeconômica, em um processo de emancipação para os povos (ARAÚJO, 2013, p. 290).

Shiva ainda observa que para a democratização do saber, os sistemas dominantes devem ser combatidos, contra a tirania e os privilégios hierárquicos que parte do impulso de desenvolvimento no contexto da globalização, no qual esse poder de sistema de saber dominante 
subjugou todos os outros se tornando antidemocrático. Assim, a democratização baseada numa “insurreição do saber subjugado" é um processo necessário tanto para proteção da natureza quanto a sobrevivência humana. Nesse sentido, o principal alerta é para a erosão da diversidade que afeta os ecossistemas, através do imperativo uniforme e monoculturas, espécies estão sendo devastadas e os projetos de modernização agrícola introduzem safras novas e uniformes nos campos de cultivo, provocando a destruição das variedades locais, com graves consequências ecológicas e sociais (2003, p. 93-94).

Para fugir desse bioimperalismo, desse domínio hegemônico dos saberes, da dominação econômica das indústrias farmacêuticas, da apropriação dos recursos naturais, Shiva defende à biodemocracia, em oposição ao bioimperalismo, de reconhecimento dos diretios das comunidades locais, das contribuições dos agricultores e membros das tribos para evolução e proteção da biodiversidade, com o objetivo de preservação da vida, e não dos lucros. Impondose a extinção da lógica perversa do financiamento da preservação da biodiversidade em troca de uma pequena porcentagem dos lucros gerados pela destruição da biodiversidade equivale a dar licença para a destruição e reduz a vida (2003, p. 110-111).

Shiva defende a biodemocracia aos direitos da sociobiodiversidade, como forma de assegurar o sustento de muitos, de justiça social, para uma possiblidade de estabilidade ecológica, favorecendo um controle para economia de subsistência e ainda, uma estrutura eficiente unidimensional, destacando que no Terceiro Mundo, é extremamente injusto que a biodiversidade do Sul, seja tratada como "herança comum da humanidade" tratada como propriedade privada de grandes empresas do Norte. Essa disparidade deve ser enfrentada com o reconhecimento dos direitos inerentes a sociobiodiversidade, através da biodemocracia, envolvendo o reconhecimento do valor intrínseco de todos os seres vivos, do reconhecimento das contribuições e direitos originais de comunidades que co- evoluíram com a biodiversidade local, como forma de justiça social e preservação ambiental (2003, p. 111-112).

Esse enfrentamento implica em que os Estados nacionais protejam esses direitos mais antigos da erosão social, cultural e ambiental da sociobiodiversidade, e especialmente quanto aos governos do Sul, que fortaleçam seu povo e sua biodiversidade, com apoio e proteção aos direitos democráticos à vida das mais variadas espécies e das comunidades diversificadas que convivem com elas, reunindo-se em um movimento de negação a perda do controle da biodiversidade por parte das comunidades locais, como forma de opor resistência e manutenção da preservação dos ecossistemas, (re) aproximando o homem da natureza, respeitando a vida. 
Segundo Araujo as configurações desse mundo globalizado, no qual emergem os direitos da sociobiodiversidade, necessitam ser compreendidas e observadas com "lentes" diversificadas e capazes de abarcar o fenômeno para operacionalizar decisões em seu contexto de complexidade e risco (2007, p. 62).

Neste mesmo posicionamento, contrário ao poder hegemônico de dominação econômica, Sen (2010, p. 16) observa o desenvolvimento como liberdade, opondo-se ao atual modelo, onde o desenvolvimento esta vinculado ao crescimento do Produto Nacional Bruto (PNB), sendo que as liberdades dependem também de disposições sociais e econômicas, como serviços de saúde e educação e respeito aos direitos civis. Enfocando, sobretudo, que o desenvolvimento tem de estar relacionado com a melhora da vida que levamos e das liberdades que desfrutamos, sendo assim, expandir as liberdades significa sermos seres sociais mais completos, interagindo com o mundo em que vivemos e influenciando esse mundo, sob um novo paradigma social, cultural, político, econômico, para a construção de um novo modelo de integração ou de uma (re) aproximação do homem com a natureza, de respeito à biodiversidade em todos os seus aspectos (2010, p. 29).

Sen ainda observa o papel dos seres humanos, como um instrumento de mudança social, podendo ir muito além da produção econômica, incluindo-se no desenvolvimento social e político, como a expansão da educação básica para melhoria da qualidade de vida e redução das desigualdades sociais, destacando que a busca por essa compreensão mais integral do papel das capacidades humanas, deve levar em consideração o bem-estar e a liberdade das pessoas; seu papel indireto influenciando a mudança social e seu papel também, na produção econômica. Nessa perspectiva, Sem observa a sobreposição de abrangências desses papeis, e a necessidade de ir muito além desse papel limitado e circunscrito do capital humano ao concebermos o desenvolvimento como liberdade (2010, p. 377).

Santos (2007, p.174) também observa esse cenário de um desenvolvimento insustentável, de risco ambiental e social, de desaparecimento de culturas e diversidade biológicas, como sendo merecedor um novo olhar, de uma nova globalização, longe das fábulas perversas e dos discursos de dominação, observando que estamos descobrindo o sentido de nossa presença no planeta, e atualmente nos deparamos com um mundo confuso e perverso, mas que pode ser o começo de uma história universal, verdadeiramente humana, com a construção de um mundo mais humano, bastando que se completem as duas grandes mutações ora em gestação: a mutação tecnológica e a mutação filosófica da espécie humana. 
Repensar a relação do homem com a natureza, na valorização dos direitos da sociobiodiversidade, alicerçada pelo ideal de uma biodemocracia, seria repensar uma outra globalização nas palavras de Santos, bem como na reconstrução da modernidade, nas palavras de Giddens ( 1991, p. 15-16), que reflete sobre a modernidade orientada para o futuro, em uma utopia de mundo pós- moderno, onde o tempo e o espaço já não seriam ordenados em sua inter-relação de historicidade, implicando em um ressurgimento de uma segurança ontológica, de consciência de um universo social sujeito a controle humano, entrelaçando o local e o global de uma maneira complexa, de uma (re) aproximação do homem com a natureza, libertando-se do modelo insustentável de exploração dos recursos naturais, contrário as monoculturas de biodiversidade, contrário às monoculturas do saber, para o restabelecimento do equilibrio e proteção do meio ambiente, dos direitos da sociobiodiversidade nos aspectos biológicos, sociais e culturais.

Esse novo olhar sob os direitos da sociobiodiversidade, através do amparo de um processo democrático, da biodemocracia, significa flexibilizar esse modelo de direito tecnicis ta, reconhecendo o direito das comunidades, da biodiversidade, das diversidades culturais, da diversidade de direitos, contrariando a atual normatividade excludente, reconhecendo principalmente o direito dos trópicos, como forma de resistência (colonialidade) e de emancipação dos povos, através dos direitos da sociobiodiversidade (ARAÚJO, 2013, p. 275).

Araujo referindo Shiva, ainda faz um alerta sobre esses dois paradigmas conflitantes da biodiversidade: sendo o primeiro mantido pelas comunidades locais, cuja sobrevivência e sustentabilidade estão ligadas ao uso e conservação da biodiversidade e o segundo mantido pelos interesses comerciais, cujos lucros estão ligados à utilização da biodiversidade global como insumos de sistemas de produção globais, centralizados e homogêneos (2013, p. 276).

Nessa perspectiva da sociobiodiversidade e da biodemocracia, como formas resistências às monoculturas, percebe-se a emergência na construção de um novo paradigma, de um novo modelo de reconhecimento do ser humano como pertencente ao meio natural, reconhecendo os direitos dos povos tradicionais, tanto quanto ao seus saber local, como quanto ao seu direito de receber a repartição dos frutos advindos da exploração de sua biodiversidade, do respeito ao meio natural. Reflete-se quanto à possibilidade do Direito desempenhar um papel transformador, conforme Silva (2013, p. 315) de ser o balizador na efetivação do equilibrio entre a técnica e conhecimento local, do efetivo reconhecimento e dos direitos fundamentais, da participação cidadã nos processos de decisão, sob o amparo de um 
processo democrático, livre da imposição das forças dominantes dos países do norte sobre os países do sul, libertos do poder hegemônico da monocultura, da dominação economia imperando sobre a relação do homem com a natureza. Esse processo de (re) aproximação, do homem com a natureza, permeia pelo contexto social, cultural, econômico e político, traz uma reflexão ao atual modelo de destruição dos recursos naturais, busca o reconhecimento dos direitos da sociobiodiversidade, como forma de justiça e emancipação social.

\section{CONCLUSÃO}

Sob uma perspectiva ampla sobre a biodiversidade nos países tropicais, em especial no Brasil, como um país mega diverso, que possibilita a observação quanto à emergência na proteção dessa riqueza natural, riqueza de diversidade biológica, riqueza de recursos minerais, riqueza de recursos hídricos, riqueza cultural e de diversidades. Nesse sentido, pela analise da relação entre sociobiodiversidade e biodemocracia, conforme a posição dos autores citados percebe-se que para uma possível (re) aproximação do homem com a natureza, deverão ser considerados aspectos de diversidade biológica, cultural e de direitos, na busca de um novo paradigma em oposição ao atual modelo de desenvolvimento insustentável de monoculturas.

Foram abordados aspectos sobre a sociobiodiversidade no mundo globalizado, com a prevalência de dominação hegemônica dos países do Norte sobre os países do Sul, enquanto diversidades culturais, naturais e de direitos, repensando quem esta ficando com as riquezas da biodiversidade? Repensando que modelo de direito pode proteger os direitos da sociobiodiversidade? Para responder a essas indagações foram abordados os conceitos de sociobiodiversidade, como forma de garantir o reconhecimento de diversidades culturais, de reconhecimento de saberes das comunidades locais e também, como forma de promover a preservação e proteção da biodiversidade. Questões que estão presentes também no aspecto jurídico, de conflito entre TRIPS, de cunho econômico sob o amparo da OMC e a CDB, que visa a proteção da sociobiodiversidade, nesse sentido mesmo com dos dispositivos Constitucionais, a legislação Brasileira ainda não é capaz de garantir efetiva proteção a diversidade biológica e cultural, na promoção dos direitos da sociobiodiversidade.

Quanto à biodemocracia, também foram analisados seus principais aspectos, no contexto da relação do homem com a natureza, como forma de preservação de uma ecocidadania, de valorização do humano, e de resistência às monoculturas, biológicas, sociais

e culturais. Observando-se ainda, que nesse contexto, o objetivo do desenvolvimento, é a exploração da biodiversidade, para obtenção de produtos e da propriedade intelectual, através 
de patentes, entrando em conflito com a $\mathrm{CDB}$, quanto a efetiva proteção da biodiversidade, constata-se a emergência em um novo modelo, de repensar o reconhecimento em torno dos conhecimentos e das sociedades tradicionais, através de um debate ético, que busque a preservação do meio ambiente e de repensar uma (re) aproximação do homem com a natureza.

Das abordagens quanto às perspectivas da sociobiodiversidade e biodemocracia como resistências às monoculturas, conclui-se que com a associação de ambas, é possível um processo de (re) aproximação do homem com a natureza, em que poderemos obter um respaldo social, econômico e político, capaz de promover uma mudança de paradigmas, para um novo modelo de proteção os direitos da sociobiodiversidade, através da biodemocracia, para além dos interesses econômicos em defesa das questões socioambientais. Assim, como forma de resistência ao imperativo econômico e político de apropriação privada de direitos intelectuais sobre biotecnologias que se sobrepõe a manutenção da sociobiodiversidade, foi observada a emergência quanto ao surgimento de um novo modelo, de um respaldo jurídico, econômico, político e social, através da biodemocracia, como princípio norteador para a composição de forças nas negociações internacionais em defesa dos interesses da sociobiodiversidade, especialmente dos países da América Latina.

\section{REFERÊNCIAS}

ARAUJO, Luiz Ernani Bonesso de. TYBUCH, Jerônimo Siqueira. Pensamento sistêmico complexo na transnacionalização ecológica. In ARAUJO, Luiz Ernani Bonesso de. VIEIRA, João Telmo. Organizadores. Eco Direito: O direito ambiental numa perspectiva sistêmicocomplexa. Santa Cruz do Sul: EDUNISC, 2007.

ARAUJO, Luiz Ernani Bonesso de. O direito da sociobiodiversidade. DIREITOS EMERGENTES NA SOCIEDADE GOLBAL- Anuário do Programa de Pós-Graduação em Direito da UFSM. Organizadores: Jerônimo Siqueira Tybusch, Luiz Ernani Bonesso de Araújo e Rosane Leal da Silva. Ijuí. 2013.

BRASIL. LEI no 13.123, de 20 de maio de 2015. Disponível em: <http://www.planalto.gov.br/ccivil_03/_Ato2015-2018/2015/Lei/L13123.htm>. Acesso em: 6 ago. 2015.

Decreto n. 1.355, de 30 de dezembro de 1994. Disponível em: < http://www.inpi.gov.br/legislacao-1/27-trips-portugues1.pdf>. Acesso em: 5 ago. 2015.

Decreto n. 2.519, de 13 de março de 1998. Disponível em:

<http://www.planalto.gov.br/ccivil_03/decreto/D2519.htm〉>. Acesso em: 4 ago. 2015. 
Decreto $\mathrm{n}^{0}$ 6.177, de $\mathbf{1}^{\circ}$ de agosto de 2007. Disponível em:

<http:/www.planalto.gov.br/ccivil_03/_ato2007-2010/2007/decreto/d6177.htm>. Acesso em 4 ago. 2015.

CAPRA, Fritjof. A teia da vida: uma nova compreensão científica dos sistemas vivos. Trad. Newton Roberval Eichemberg. São Paulo, Cultrix, 2006.

DIREITOS EMERGENTES NA SOCIEDADE GLOBAL- Anuário do Programa de PósGraduação em Direito da UFSM. Organizadores: Jerônimo Siqueira Tybusch, Luiz Ernani Bonesso de Araújo e Rosane Leal da Silva. Ijuí. 2013.

GIDDENS, Anthony. As consequências da modernidade. Trad. Raul Fiker. São Paulo, Unesp, 1991.

KISHI, Sandra Akemi Shimada. Principiologia do acesso ao patrimônio genético e ao conhecimento tradicional associado. In PLATIAU, Ana Flávia Barros. VARELLA, Marcelo Dias. Organizadores. Diversidade Biológica e conhecimentos tradicionais. Belo Horizonte. Del Rey, 2004.

MARTINS, Marcio e SANO, Paulo Takeo. Biodiversidade Tropical. São Paulo, Ed. UNESP, 2009.

MOSCOVICI, Serge. Natureza: para pensar a ecologia. Trad. Marie Louise Trindade Conilh de Beyssac e Regina Mathieu. Rio de Janeiro; Instituto Gaia, 2007.

ONU. Relatório de Desenvolvimento Humano 2013, apresentado pelo Programa das Nações Unidas para o Desenvolvimento (PNUD). Disponível em: < http://amazonia.org.br/2013/03/relat\%C3\%B3rio-da-onu-prev\%C3\% AA-cat\%C3\%A1 strofeambiental-no-mundo-em-2050/>>. Acesso em: 4 ago. 2015.

OST, François. A natureza à margem da lei: a ecologia à prova do direito. Lisboa: Instituto Piaget, 1995.

PORTO-GONÇALVES, Carlos Walter. A globalização da natureza e a natureza da globalização. 3. ed. Rio de Janeiro: Civilização Brasileira, 2012.

QUIJANO, Anibal. Colonialidade do poder, eurocentrismo e América Latina. Buenos Aires. 2005.p. 121.

SACHS, Ignacy. Desenvolvimento: includente, sustentável, sustentado. Rio de Janeiro: Garamond, 2008.

SANTILI, Juliana. Conhecimentos tradicionais associados à biodiversidade: elementos para a construção de um regime jurídico sui generis de proteção. In. Diversidade Biológica e conhecimentos tradicionais. Orgs. DIAS, Marcelo Varella; PLATIAU, Ana Flávia Barros. Belo Horizonte: Del Rey, 2004.

Socioambientalismo e novos direitos. São Paulo: Peirópolis, 2005.

SANTOS, Boaventura de Sousa; MENESES, Maria Paula (Orgs.). Epistemologias do Sul. Coimbra: Almedina, 2009.

SHIVA, Vandana. Monoculturas da Mente: perspectivas da biodiversidade ebiotecnologia. Trad. Dinah de Abreu Azevedo. São Paulo; Gaya, 2003. 
SILVA, Maria Beatriz Oliveira da. Direito ao desenvolvimento e à sustentabilidade ambiental: diálogos e confitos no balizamento jurídico do desenvolvimento (sustentável). Direitos Emergentes Na Sociedade Golbal- Anuário do Programa de Pós-Graduação em Direito da UFSM. Organizadores: Jerônimo Siqueira Tybusch, Luiz Ernani Bonesso de Araújo e Rosane Leal da Silva. Ijuí. 2013.

TYBUSCH, Jerônimo Siqueira. NUNES, Denise Silva. A problemática da biopirataria: reflexões a partir da geopolítica e dos direitos da sociobiodiversidade. REDESG - Revista Direitos Emergentes na Sociedade Global. Universidade Federal de Santa Maria, v. 2, n.1, jan. jun. / 2013. Disponível em: <http://cascavel.ufsm.br/revistas/ojs2.

2.2/index.php/REDESG/issue/view/576/showToc\#.VcIdEflViko>. Acesso em: 5 ago. 2015.

VIEIRA, Vinícius Garcia. Direito da Biodiversidade e América Latina: a questão da propriedade intelectual. Ijuí, RS; Unijuí, 2012.

WILSON, E. O. A situação atual da diversidade biológica. In Wilson, E. O. Biodiversidade. Rio de Janeiro, Nova Fronteira, 1997.

ZHOURI, Andréa. LASCHEFSKI, Klemens. Desenvolvimento e conflitos ambientais: um novo campo de investigação. In ZHOURI, Andréa. LASCHEFSKI, Klemens. Organizadores. Belo Horizonte. UFMG, 2010. 